University of Wollongong

Research Online

Faculty of Engineering and Information

Faculty of Engineering and Information

Sciences - Papers: Part A

Sciences

$1-1-2012$

Control of five-level flying capacitor based active-neutral-point-clamped converter for grid connected wind energy applications

Sridhar R. Pulikanti

University Of Wollongong, sridhar@uow.edu.au

Kashem Muttaqi

University of Wollongong, kashem@uow.edu.au

D Suntanto

University of Wollongong

Follow this and additional works at: https://ro.uow.edu.au/eispapers

Part of the Engineering Commons, and the Science and Technology Studies Commons

Research Online is the open access institutional repository for the University of Wollongong. For further information contact the UOW Library: research-pubs@uow.edu.au 


\title{
Control of five-level flying capacitor based active-neutral-point-clamped converter for grid connected wind energy applications
}

\author{
Abstract \\ Integration of wind energy sources into the distribution grid affects the voltage profile that could be \\ stabilized through the grid reinforcement or limiting the active power injection. This paper presents a \\ control strategy to regulate the voltage at point of common coupling (PCC) through reactive power \\ exchange to the grid. The reactive power capability of the grid-connected hybrid multilevel converter is \\ based on the voltage sensitivity of the distribution grid at PCC. A hybrid five-level multilevel converter \\ referred as flying capacitor (FC) based active-neutral-point-clamped (ANPC) converter is considered. It is \\ an arrangement of a three-level ANPC converter and a two-level cell. Also, a control strategy is proposed \\ to regulate the FCs voltages of the grid-connected hybrid multilevel converter at their required values. The \\ proposed FC control strategy provides extra freedom to regulate the dc-link capacitor voltages with dc- \\ offset injection technique. Simulation studies demonstrate the performance of the proposed control \\ strategies for the system considered. (c) 2012 IEEE.
}

\section{Keywords}

wind, grid, converter, clamped, point, applications, neutral, control, active, capacitor, flying, level, energy, five, connected

\section{Disciplines}

Engineering | Science and Technology Studies

\section{Publication Details}

S. R. Pulikanti, K. Muttaqi \& D. Suntanto, "Control of five-level flying capacitor based active-neutral-pointclamped converter for grid connected wind energy applications," in Industry Applications Society Annual Meeting (IAS), 2012 IEEE, 2012, pp. 1-9. 


\section{Control of Five-level Flying Capacitor Based Active-Neutral-Point-Clamped Converter for Grid Connected Wind Energy Applications}

\author{
Sridhar R. Pulikanti \\ Member IEEE \\ Endeavour Energy Power Quality \\ and Reliability Centre \\ University of Wollongong \\ Wollongong, 2252, Australia \\ Email: sridhar@uow.edu.au
}

\author{
Kashem Muttaqi \\ SeniorMember IEEE \\ Endeavour Energy Power Quality \\ and Reliability Centre \\ University of Wollongong \\ Wollongong, 2252, Australia \\ Email:kashem@uow.edu.au
}

\author{
Danny Suntanto \\ Senior Member IEEE \\ Endeavour Energy Power Quality \\ and Reliability Centre \\ University of Wollongong \\ Wollongong, 2252, Australia \\ Email:soetanto@uow.edu.au
}

\begin{abstract}
Integration of wind energy sources into the distribution grid affects the voltage profile that could be stabilized through the grid reinforcement or limiting the active power injection. This paper presents a control strategy to regulate the voltage at point of common coupling (PCC) through reactive power exchange to the grid. The reactive power capability of the grid-connected hybrid multilevel converter is based on the voltage sensitivity of the distribution grid at PCC. A hybrid fivelevel multilevel converter referred as flying capacitor (FC) based active-neutral-point-clamped (ANPC) converter is considered. It is an arrangement of a three-level ANPC converter and a twolevel cell. Also, a control strategy is proposed to regulate the FCs voltages of the grid-connected hybrid multilevel converter at their required values. The proposed $\mathrm{FC}$ control strategy provides extra freedom to regulate the dc-link capacitor voltages with dcoffset injection technique. Simulation studies demonstrate the performance of the proposed control strategies for the system considered.
\end{abstract}

Index Terms-Active-neutral-point-clamped (ANPC) converter, permanent magnet synchronous generator (PMSG), voltage control, distribution systems

\section{INTRODUCTION}

In existing distribution network, the penetration of distributed generation and electricity from renewable sources have been increasing significantly especially intermittent energy resoruces that poses a potential impact on the network operation and control [1]. The intermittent renewable energy sources can be integrated with distribution network in various multi-string topologies [1], [2]. A wind farm with internal dc network arrangement was discussed in [1]. The dc-distribution system involves a better integration of distribution generators and the storage systems, compared with the ac-grid with respect to bi-directional power exchange and power quality [3], [4]. Whereas in [5], the protection schemes were proposed for permanent magnet synchronous generator (PMSG) wind turbines farm connected in parallel to dc-link. In variablespeed wind turbine technologies, the PMSG has received increased attention because of its operation at high power factor, high efficiency and increased reliability due to its selfexcitation property [6].

A power conditioning system of a variable-speed wind energy system, especially in small capacity PMSG wind system, consists of a rectifier, a dc-dc boost converter and a gridconnected converter [7]. The grid-connected voltage source converters (VSCs) are integrated with the distribution network to regulate the power flow or optimize the power factor by controlling active and reactive power exchange to grid using the control techniques such as synchronous frame, hysteresisbased strategies [3], [8]. Typically, a two-level VSC have been used to integrate the renewable energy source with the grid. In recent developments in power electronic circuit topologies and control stratgies, renewable energy systems have become economically a viable solution [1].

Multilevel converters provide significant advantages over the two-level converter, including but not limited to lower harmonic distortion, lower electro-magnetic interference, low stress of the semiconductor switching devices and high efficiency [9], [10]. In [11], a control strategy for a three-phase three-level neutral point clamped (NPC) converter integrating PMSG to a grid was proposed based on virtual flux estimation. A three-level dc-dc boost converter was proposed for threelevel NPC converter in [12] to track the maximum power and regulate dc-link capacitor voltages. Moreover in [13], a multilevel control strategy was proposed for three-phase three-level grid-connected converter based wind energy system where the external level controller was responsible to determine the active and reactive power exchange to grid. However, an increase in the number of levels of the conventional multilevel converters increases the complexity in controlling the voltage across the dc-link capacitors of NPC converter; the capacitors of the flying capacitor (FC) converter and the number of isolated power supplies of the cascaded $\mathrm{H}$ bridge converter. Hybrid multilevel converter topologies have been introduced using different arrangements of conventional multilevel converters. One of them is the FC based fivelevel active neutral point clamped (ANPC) converter [14]. The redundant switching states of the FC based five-level ANPC converter are utilized to control the voltage across FC and the dc-link capacitor voltages which is acheived by simplifying the modulation of the converter [15].

In this paper, a cascaded control strategy of FC based ANPC converter for wind energy applications to exchange active 


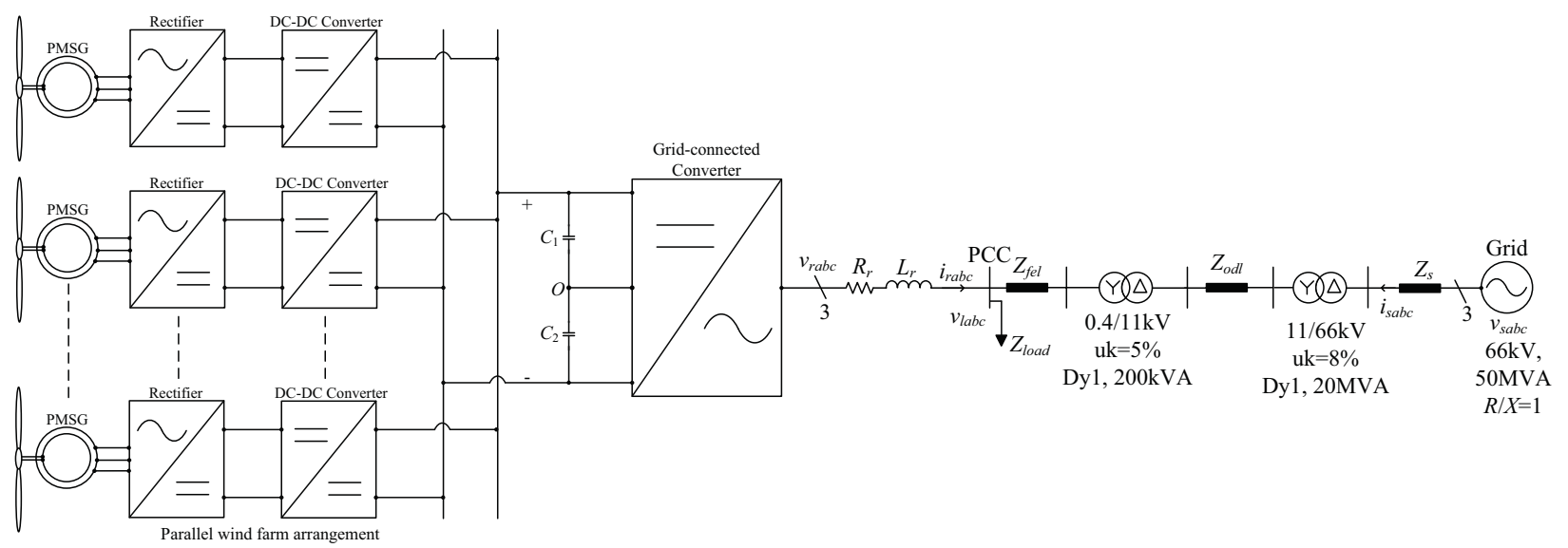

Fig. 1. A connection of permanent magnet synchronous generator (PMSG) based wind farm to grid through five-level FC based ANPC converter

and reactive power to grid is discussed. The control strategy maintains the point of common coupling (PCC) voltage by reactive power exchange whose capability is based on the voltage sensitivity of the distribution network at PCC. The required number of output voltage levels is achieved by regulating the voltage across $\mathrm{FC}$ at its reference level. A switching-frequency optimal (SFO) pulse-width modulation based flying capacitor voltage control strategy is proposed which provides extra freedom to control the dc-link voltages in conjunction with dc-offset injection method.

This paper is organized in the following way. In Section II, the maximum extraction of power from wind turbine is discussed. In Section III, the operation principles of FC based ANPC converter are presented.The FC based ANPC converter control strategy to control FCs and dc-link capacitors voltage using switching-frequency optimal modiulation is discussed in Section IV. In Section V, the cascaded controller for the grid-connected converter is illustrated. The performance evaluation of the considered wind energy system configuration is discussed for various control modes in Section VI and finally conclusions are summarized in Section VII.

\section{MAXIMUM Wind POWER EXtraction}

The steady state characteristics of a wind turbine can be described by the total power in the wind and the mechanical power of the wind turbine [6]. The amount of power captured by the wind turbine is given in (1)

$$
P_{w}=0.5 \rho_{\mathrm{air}} A C_{P}(\lambda, \beta)\left(\frac{\omega_{\mathrm{m}} R}{\lambda}\right)^{3}
$$

where $\rho_{\text {air }}$ is the air density $\left(=1.225 \mathrm{~kg} / \mathrm{m}^{3}\right), v_{\mathrm{w}}$ is the wind speed ( $\mathrm{m} / \mathrm{s}), A$ is the swept area of blades $\left(\mathrm{m}^{2}\right), R$ is the radius of the turbine $(\mathrm{m})$, and $C_{\mathrm{P}}$ is called the power coefficient of the wind turbine (dimensionless) which is a function of the tip-speed ratio $(\lambda)$ and the pitch angle $(\beta) . \omega_{\mathrm{m}}$ is the angular speed of the turbine rotor $(\mathrm{rad} / \mathrm{s})$. The wind turbine can produce maximum power when the turbine operates at maximum $C_{\mathrm{P}}$. Therefore, it is necessary to keep the rotor speed at an optimum value of the tip-speed ratio $(\lambda)$. The optimum power of wind turbine is given as (2).

$$
P_{\mathrm{w}, o p t}=K_{o p t}\left(\omega_{\mathrm{m}, o p t}\right)^{3}
$$

where

$$
K_{o p t}=0.5 \rho_{\mathrm{a} i r} A C_{\mathrm{P}, o p t}(\lambda, \beta)\left(\frac{R}{\lambda_{o p t}}\right)^{3}
$$

Therefore the optimum torque can be given in eq. (4)

$$
T_{\mathrm{m}, o p t}=K_{o p t}\left(\omega_{\mathrm{m}, o p t}\right)^{2}
$$

The maximum power extraction can be obtained by operating the turbine at optimum rotor speed. The optimum power can be calculated from the optimum torque given in (4).

The maximum power point tracking from the variable-speed wind turbine is achieved by controlling the duty cycle of dcdc converter. Under steady-state condition, the boost converter is operated in continous conduction mode. The maximum power point tracking algorithm based on the generator speed proposed in [6], [16] has been implemented.

\section{FLying CAPACITOR BASED ANPC CONVERTER OPERATIONAL PRINCIPLES}

The phase-leg of the five-level FC based ANPC converter is shown in Fig. 2. The basic requirements of FC based ANPC converter is to operate the outer switches $\left(S_{x 5}, S_{x 6}, S_{x 7}\right.$ and $S_{x 8}$ ) at the fundamental frequency of the output voltage [14]. The five-level FC based ANPC converter consists of eight switching states which generate the five different voltage levels at the output as shown in Table I. The voltage withstand capacity of the outer switches is twice that of $S_{x 1}, S_{x 2}, S_{x 3}$ and $S_{x 4}$. The output phase voltage, $v_{r x O}$, is given in (5):

$$
v_{r x O}=V_{d c}\left[2\left(S_{x 5}-1\right)+\left(S_{x 3}+S_{x y 1}\right)\right]
$$

where $V_{d c}$ is assumed to be voltage across the FC, $C_{f, x 1}$. The current through the $\mathrm{FC} C_{f, x}$ can then be expressed as:

$$
i_{C f, x}=\left(S_{x 3}-S_{x y 1}\right) i_{r x}
$$


TABLE I

SWITCHING StATES OF THE FIVE-LEVEL ANPC CONVERTER

\begin{tabular}{c|c|c|c|c|c|c|c|c|c}
\hline & $S_{x 3}$ & $S_{x 4}$ & $S_{x 5}$ & $S_{x 6}$ & $S_{x 7}$ & $S_{x 8}$ & $S_{x y 1}$ & $S_{x y 2}$ & $V_{r O}$ \\
\hline \hline$V_{1}$ & \multirow{2}{*}{0} & \multirow{2}{*}{1} & 0 & 1 & 0 & \multirow{2}{*}{1} & 0 & 1 & $-2 V_{d c}$ \\
\hline$V_{2}$ & & & & & & & 1 & 0 & $-V_{d c}$ \\
\hline$V_{3}$ & \multirow{2}{*}{1} & 0 & 0 & 1 & 0 & \multirow{2}{*}{1} & 0 & 1 & $-V_{d c}$ \\
\hline$V_{4}$ & & & & & & & 1 & 0 & 0 \\
\hline$V_{5}$ & 0 & 1 & 1 & 0 & 1 & 0 & 0 & 1 & 0 \\
\hline$V_{6}$ & & & & & & & 1 & 0 & $V_{d c}$ \\
\hline$V_{7}$ & \multirow{2}{*}{1} & \multirow{2}{*}{0} & \multirow{2}{*}{0} & \multirow{2}{*}{0} & \multirow{2}{*}{0} & 0 & 1 & $V_{d c}$ \\
\hline$V_{8}$ & & & & & & & 1 & 0 & $2 V_{d c}$ \\
\hline
\end{tabular}

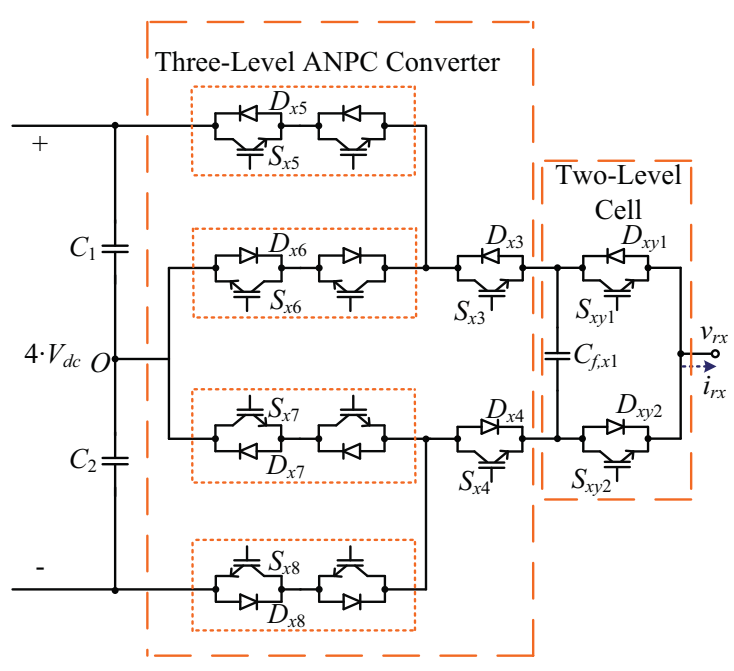

Fig. 2. Phase-leg of a five-level ANPC converter

The rate of change of the voltage across FC can be expressed as:

$$
\frac{d}{d t} v_{c f, x}=\frac{i_{r x}}{C_{f, x}}\left(S_{x 3}-S_{x y 1}\right)
$$

The voltage across FCs should be maintained at $V_{d c}$ which is affected by the switching states $V_{2}, V_{3}, V_{6}$ and $V_{7}$. During the switching states $V_{3}$ and $V_{6}$ the neutral point ' $O$ ' is connected to the load through flying capacitor. By utilizing these switching states, the neutral point voltage of the converter can be controlled.

\section{SWITCHING-FREQUENCY OPTIMAL (SFO) Modulation And CONVERTER Voltage Control}

In literature, the multilevel carrier pulse-width modulation (PWM) have been categorized into level-shifted and phaseshifted carrier PWM methods. In [17], a carrier-based PWM technique was considered that was based on the subtraction of the instantaneous average of the maximum and minimum of the three reference voltages from each of the individual reference voltages shown in Fig. 3. This technique increases the utilization of the dc-link voltage. The switching wavefroms generated by comparing the modulating waveform with the carrier waveforms shown in Fig. 3 (b). The switching patterns
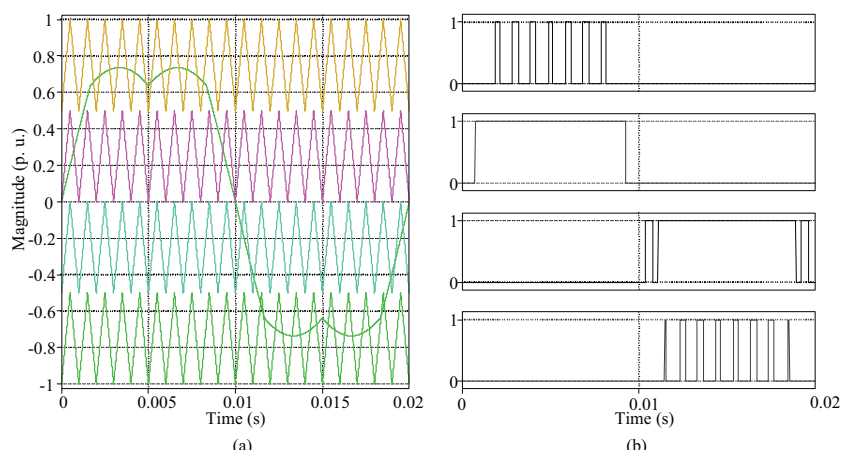

Fig. 3. (a) Carrier waveforms and modulating waveform $m_{a}=0.8$, $f_{s}=1000 \mathrm{~Hz}$ (b) Switching Signals
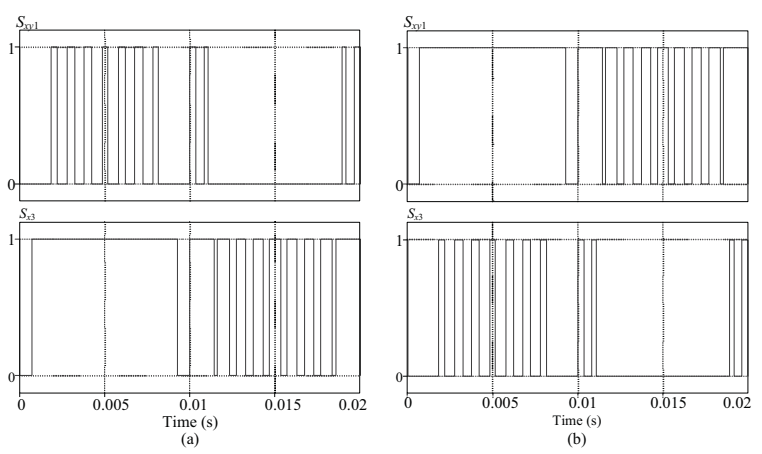

Fig. 4. Switching patterns for switches $S_{x y 1}$ and $S_{x 3}$ (a) FC discharging first half period and charging second half period (b) FC charging first half period and discharging second half period

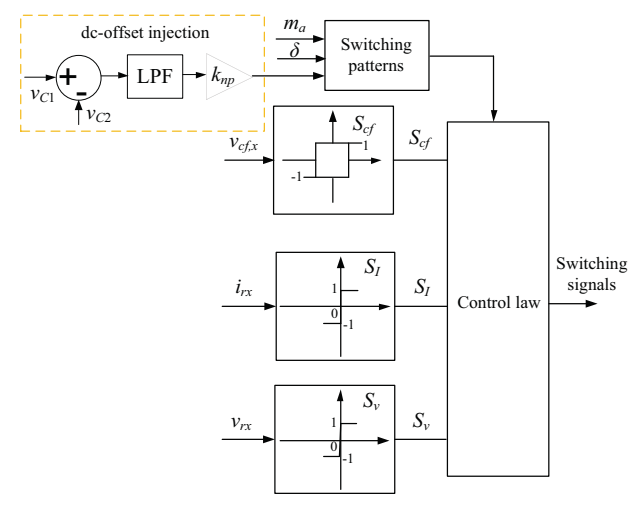

Fig. 5. Schematic diagram of proposed FC controller

are acheived by simplifying switching wavefroms that regulates the FC voltage are shown in Fig. 4.

The charging or discharging of the FC takes place at the middle voltage levels $\pm V_{d c}$ and depends upon polarity of the output current as mentioned in Table I. The voltage across the FC which should be maintained at $V_{d c}$ and it is affected by the switching states $V_{2}, V_{3}, V_{6}$, and $V_{7}$. The voltage across the FC could be regulated using the switching states resulting in 


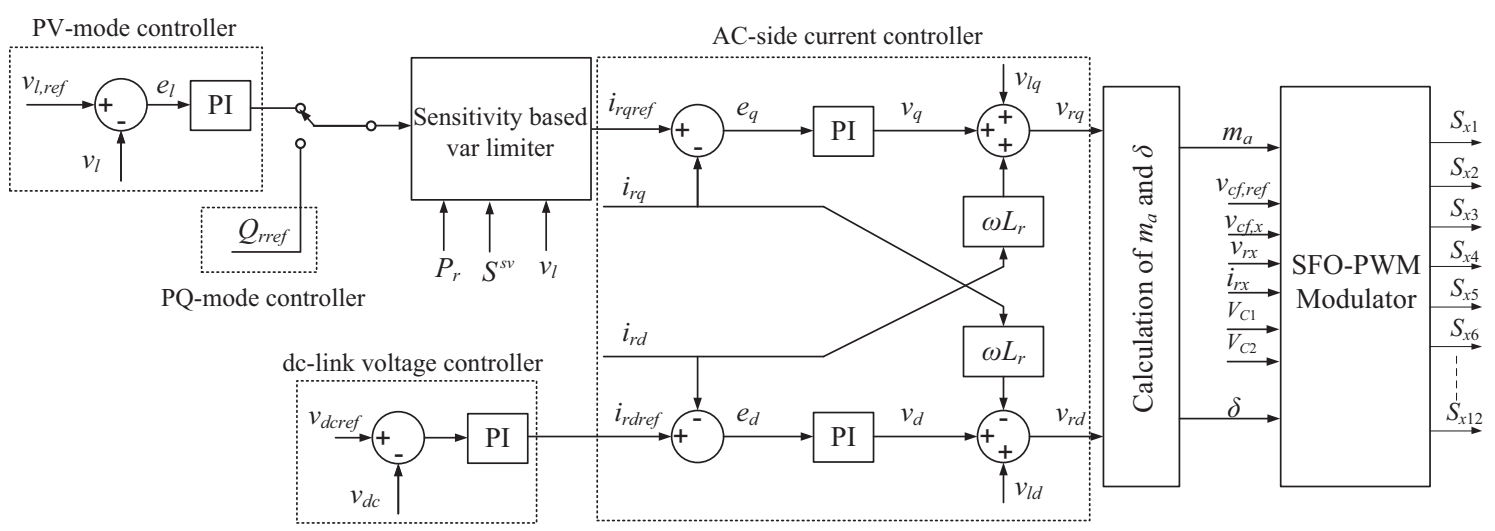

Fig. 6. Schematic diagram of the FC based ANPC converter controller

time intervals of charging and discharging being equal over a fundamental period. Two patterns of switching functions for switches $S_{x y 1}$ and $S_{x 3}$ can be evolved that can generate the five-level output voltage waveform as shown in Fig. 4. These patterns are chosen in order to regulate the voltage across FC at its reference level based on the polarity of the output current, the polarity of the output voltage and the voltage across $\mathrm{FC}$, which simultaneously controls the voltage across the dc-link capacitors. The block diagram of the FC voltage controller is shown in Fig. 5. The voltage across FC is compared in a hysteresis comparator and the band of the hysteresis controller defines the switching frequency of each switches. The reference voltage level of each FC is one-quarter of the dc-link voltage. If the $\mathrm{FC}$ voltage is higher than upper band limit $\left(V_{d c}+h\right)$, capacitor voltage state $\left(S_{c f}\right)$ is 1 which implies that the respective FC needs to be discharged. If it is less than lower band limit $\left(V_{d c}-h\right), S_{c f}$ is -1 and the respective FC needs to be charged. The polarity of the output current determines the status $\left(S_{I}\right)$, where $S_{I}$ is 1 for positive current and -1 for negative current.

By using the polarity of the fundamental output phase voltage, the switching state $V_{4}$ or $V_{5}$ is selected so that the switching frequency of the clamping switches $\left(S_{x 5}-S_{x 8}\right)$ equals to the fundamental output frequency. The band of the hysteresis controller determines the selection of switching states that influences the neutral point voltage. By appropriate selection of the band limits of the controller the neutral point voltage deviation could be minimized. The dc-offset injection [14] with proposed FC controller provides extra freedom of control to regulate the neutral point voltage of the converter.

\section{CAscaded Controller for Grid-Connected CONVERTER}

The phase voltages at PCC are denoted by $v_{l a}, v_{l b}$, and $v_{l c}$. The converter output voltages and currents are denoted by $v_{r a}, v_{r b}, v_{r c}$ and $i_{r a}, i_{r b}, i_{r c}$ respectively. The inductance and resistance of the ac-reactor are denoted by $R_{r}$ and $L_{r}$ respectively.

The mathematical equations that characterize the behavior of voltages at PCC are given in (8)-(10):

$$
\begin{aligned}
& v_{r a}=R_{r} i_{r a}+L_{r} \frac{d}{d t}\left(i_{r a}\right)+v_{l a} \\
& v_{r b}=R_{r} i_{r b}+L_{r} \frac{d}{d t}\left(i_{r b}\right)+v_{l b} \\
& v_{r c}=R_{r} i_{r c}+L_{r} \frac{d}{d t}\left(i_{r c}\right)+v_{l c}
\end{aligned}
$$

The converter ac-side variables are transformed into the rotating $d q$-reference frame, where the $d q$-reference frame is synchronized with the PCC voltage. They are expressed in a matrix form as,

$$
\left[\begin{array}{c}
v_{r d}-v_{l d} \\
v_{r q}-v_{l q}
\end{array}\right]=\left[\begin{array}{cc}
R_{r}+L_{r} \frac{d}{d t} & -\omega L_{r} \\
\omega L_{r} & R_{r}+L_{r} \frac{d}{d t}
\end{array}\right]\left[\begin{array}{c}
i_{r d} \\
i_{r q}
\end{array}\right]
$$

The real and reactive currents $i_{r d}$ and $i_{r q}$ respectively are regulated in order to control the real and reactive power transfer between the converter and the distribution network.

The voltage change at PCC caused by the active power and reactive power exchange of the converter and required load power is given in (12)

$$
\begin{aligned}
\Delta V= & \mid \frac{R_{s}\left(P_{l}-P_{r}\right)+X_{s}\left(Q_{l}-Q_{r}\right)}{V_{l}} \\
& -\frac{j X_{s}\left(P_{l}-P_{r}\right)-R_{s}\left(Q_{l}-Q_{r}\right)}{V_{l}} \mid
\end{aligned}
$$

where $P_{r}, Q_{r}$ are active power and reactive power exchange between converter and grid and $P_{l}, Q_{l}$ are required active and reactive power of the load at point of common coupling. The source resistive impedance and reactive impedance are denoted by $R_{s}, X_{s}$ respectively. From (12) the relationship between the ac-source voltage and PCC voltage is obtained as shown in (13).

$$
\begin{aligned}
V_{s}^{2}= & {\left[\frac{R_{s}\left(P_{l}-P_{r}\right)+X_{s}\left(Q_{l}-Q_{r}\right)}{V_{l}}\right]^{2} } \\
& +\left[\frac{j X_{s}\left(P_{l}-P_{r}\right)-R_{s}\left(Q_{l}-Q_{r}\right)}{V_{l}}\right]^{2}
\end{aligned}
$$

The sensitivity of the voltage at PCC plays a vital role in exchange of real and reactive power between the converter and 


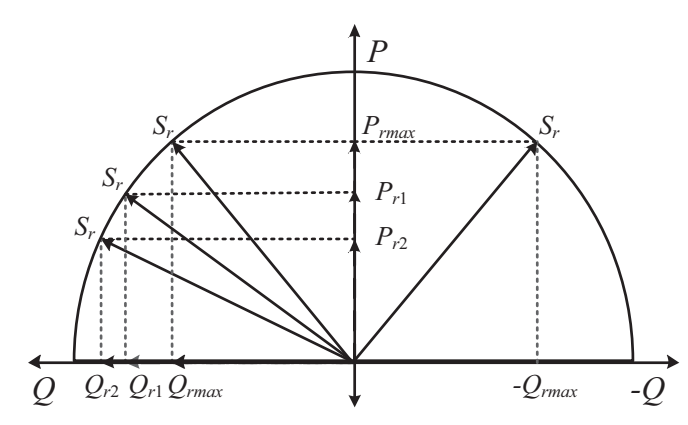

Fig. 7. kVA plot of FC based ANPC converter

the grid. The voltage sensitivity is different for various $R_{s} / X_{s}$ ratios. The change in voltage at PCC due to active/reactive power variations at an operating point can be defined as given in (14).

$$
\Delta V=S_{p r}^{s v} \Delta P+S_{q r}^{s v} \Delta Q
$$

where $S_{p r}^{s v}, S_{q r}^{s v}$ are the voltage sensitivity parameters for active power and reactive power exchange at PCC respectively.

The capacity of the FC based ANPC converter is limited by the current carrying capability of the converter switches [18]. The apparent power capacity of FC based ANPC converter $S_{r}$ in terms of maxmium active power generated through wind farm $P_{r \max }$ and voltage sensitivity parameters is given by (15).

$$
S_{r}=P_{r \max } \sqrt{1+\tan ^{2}\left(\cos ^{-1} \frac{S_{q r}^{s v}}{\sqrt{\left(S_{p r}^{s v}\right)^{2}+\left(S_{q r}^{s v}\right)^{2}}}\right)}
$$

For various amount of $P_{r}$ injection, the magnitude of $Q_{r}$ injection changes as shown in Fig. 7. The reactive power capability of the grid-connected system is based on voltage sensitivity parameters at PCC and $Q_{r}=\sqrt{S_{r}^{2}-P_{r}^{2}}$ [19]-[20]. The voltage sensitivity parameters are determined by using incremental power injection method [21]. For determined voltage sensitivity parameters, $Q_{r \max }$ is the maximum reactive power injected or absorbed into the grid at maximum wind power generation.

The cascaded controller of FC based ANPC converter shown in Fig. 6 consists of two loops. The inner loops regulate the currents injected to the grid using current controller and the outer loops regulate the dc-link voltage and the reactive power delivered to the grid. The dynamics of the dc-link capacitor power balance is given by (16).

$$
C_{e q} V_{d c}\left(\frac{d V_{d c}(t)}{d t}\right)=P_{d c}(t)-P_{r}(t)
$$

where $C_{e q}=\frac{C}{2}\left(C_{1}=C_{2}=C\right)$ is the equivalent dc-link capacitance of the FC based ANPC converter, $P_{d c}(t)$ is the total active power generated from wind energy system and $P_{r}(t)$ is the total power injected into the grid.

PCC voltage controller, shown in Fig. 6, maintains the $\mathrm{PCC}$ voltage at its reference value by reactive power transfer
TABLE II

PARAMETERS OF GRID-CONNECTED SYSTEM

\begin{tabular}{cc}
\hline Nominal active power generation & $18 \mathrm{~kW}$ \\
\hline Flying capacitor, $C_{f, x}(x=a, b, c)$ & $1000 \mu \mathrm{F}$ \\
\hline dc-link capacitor, $C_{1}, C_{2}$ & $10000 \mu \mathrm{F}$ \\
\hline dc-link voltage & $700 \mathrm{~V}$ \\
\hline Converter-side inductance, $L_{r}$ & $5.65 \mathrm{mH}$ \\
\hline Converter-side resistance, $R_{r}$ & $0.17 \Omega$ \\
\hline Line frequency & $50 \mathrm{~Hz}$ \\
\hline Carrier frequency & $4 \mathrm{kHz}$ \\
\hline
\end{tabular}

between the FC based ANPC converter and the distribution network. The PCC voltage is controlled through an antiwindup PI controller that generates a reference reactive current component, $i_{\text {rqref }}$. The anti-windup PI controller is necessary to ensure the required output reactive power proportional to its limitations. The PCC voltage is controlled based on the following control law

$$
i_{\text {rqref }}=\left\{\begin{array}{l}
K_{\text {ppcc }} e_{l}+K_{\text {ipcc }} \int_{0}^{t} e_{l} \mathrm{~d} t- \\
K_{\text {ipcc }}\left(K_{\text {rl }}\left(i_{\text {rqref }}-i_{S}\right) \int_{0}^{t} e_{l} \mathrm{~d} t\right.
\end{array}\right.
$$

where $e_{l}=v_{l, r e f}-v_{l}, i_{S}$ is the saturated output current component and $K_{r l}$ is the feedback gain. The value of $K_{r l}$ is chosen such that it enables the controller to come out of saturation quickly.

\section{Performance eValuation of the System}

A wind farm consisting of three 6kW PMSG based wind turbines was connected to grid-side converter through dedicated diode rectifier and dc-dc converter to extract maximum power based on the generator speed as shown in Fig. 1. The single-line diagram of a distribution system shown in Fig. 1 consists of equipment parameters that are comparable to real power systems. The grid-connected wind energy system is modelled using the developed control strategies in the Matlab/Simulink and PLECS environments with the parameters listed in Table II. The voltage sensitivity parameters at PCC were estimated through power injection method. The ratio of voltage sensitivities $S_{p r}^{s v}$ and $S_{q r}^{s v}$ is determined to be 0.475 . The apparent power capacity of FC based ANPC converter was found substituting the obtained voltage sensitivities in (15) to be $19.93 \mathrm{kVA}$. From above calculation, the FC based ANPC converter provides $8.55 \mathrm{kVAr}$ at maximum wind power generation. The wind profile was considered such that the wind speed fluctuates as shown in Fig. 8 . The band limit $( \pm h)$ of the hysteresis controller was considered to be $\pm 5 \%$ of $V_{d c}$. The dc-offset was injected such that neutral point deviation was minimal.

Based on power factor control or voltage control at PCC the PMSG based grid-connected system can be represented as PQ or PV bus [22]. To discuss the operating capabilities and limits of PMSG based grid-connected system the PCC was considered as PV or PQ bus.

Initially, the system was considered without the wind energy system integration at PCC. At $t=2 \mathrm{~s}$, a load $l_{1}=30 \mathrm{~kW}$ was 


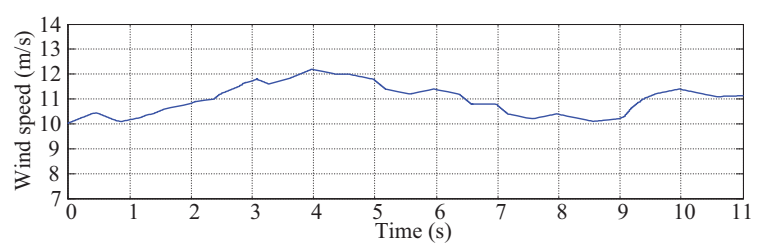

Fig. 8. Wind profile on the turbine
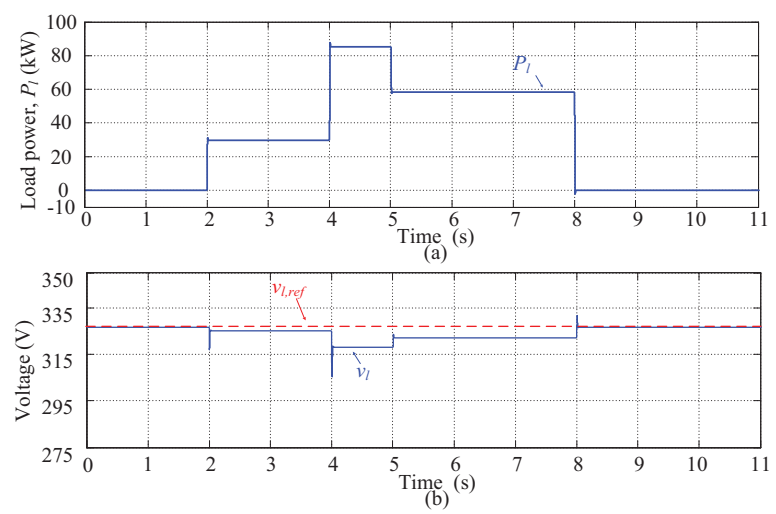

Fig. 9. Without wind energy integration at PCC: (a) active load power, $P_{l}$ (b) PCC voltage, $v_{l}$

connected to the grid through a breaker at PCC. Another load $l_{2}=60 \mathrm{~kW}$ was connected to the grid at $t=4 \mathrm{~s}$. The loads $l_{1}$ and $l_{2}$ were disconnected from the grid at $\mathrm{t}=5 \mathrm{~s}$ and $\mathrm{t}=8 \mathrm{~s}$ respectively. Fig. 9 (a) and (b) illustrates the behaviour of required load power $P_{l}$ and voltage due load variation at PCC respectively.

\section{A. PMSG Based Grid-Connected System as PV Bus}

Grid-connected system operates as a PV bus by regulating active power and PCC voltage. The exchange of reactive power into the grid based on the wind power generation and PCC voltage were investigated by maintaining the PCC voltage at its reference level. The total active power generated from the wind energy system was transferred to the grid using dc-link voltage controller shown in Fig. 6. The reference value of the dc-link voltage was set to $700 \mathrm{~V}$. At maximum wind power generation, the FC based ANPC converter operates at 0.9 power factor. Three cases were considered to take into account the possible combinations of active and reactive power exchange to regulate the PCC voltage.

In case 1 , the active power generated from wind energy system was injected into the grid. Fig. 10(a) illustrates the behavior of active power exchange at PCC for various loads where $P_{s}$ is grid active power. The variation of load at PCC was same as that considered in the above initial case. The $P_{r}$ injection into the grid slightly increases the PCC voltage during $t=0$ to $2 \mathrm{~s}$ as shown in Fig. 10(b). The voltage at PCC was improved during load variation at PCC as shown in Fig. 10(b). The voltage across dc-link was controlled at its reference level as shown in Fig. 10(c). Fig. 11 shows the voltage regulation across flying capacitors at their reference voltage levels with ripple magnitude equal to the band limit of the
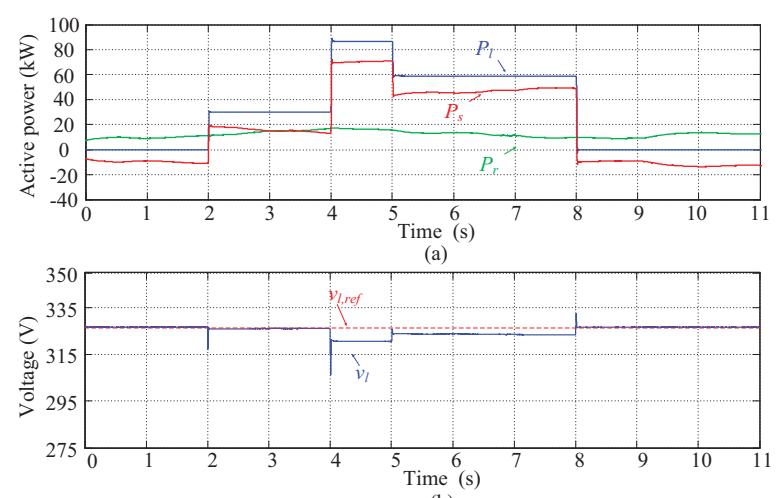

(b)

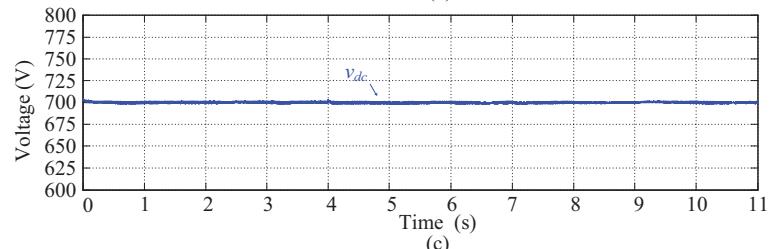

(c)

Fig. 10. PV mode, case 1: (a) active power exchange at PCC, $P_{r}, P_{s}, P_{l}$ (b) PCC voltage, $v_{l}$ (c) the voltage across dc-link, $v_{d c}$
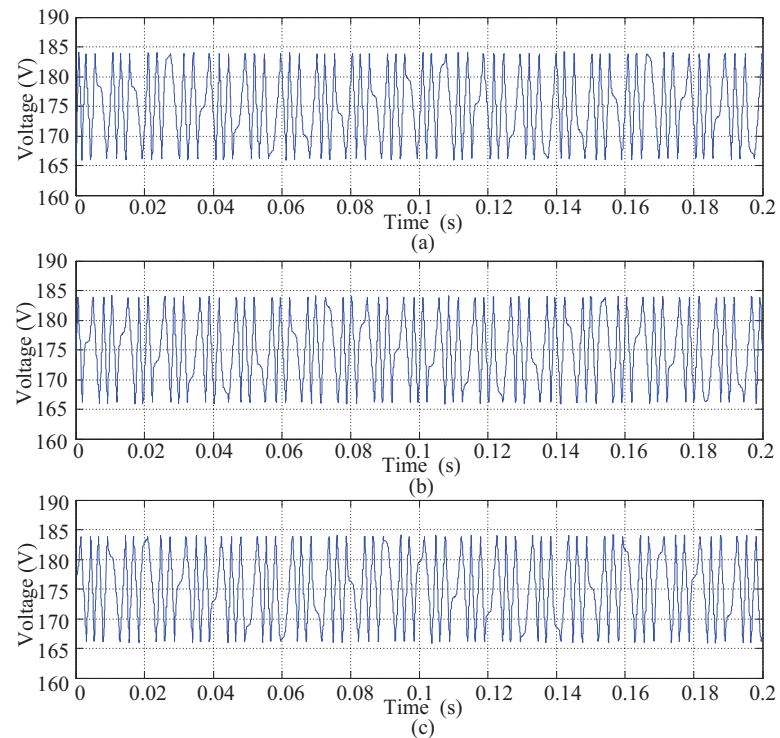

Fig. 11. PV mode, case 1: voltage across (a) $C_{f, a}$ (b) $C_{f, b}$ (c) $C_{f, c}$ [snapshot from $t=3.5 \mathrm{~s}$ to $3.7 \mathrm{~s}$ ]

hysteresis controller. The voltages across the dc-link capacitors were regulated at their reference levels under the proposed FC control and dc-offset injection as shown in Fig. 12(a) and (b).The voltages across FCs and dc-link capacitors of the grid-side converter generates the line-to-line voltage shown in Fig. 13.

In case 2, the active power injection into the grid slightly increases the PCC voltage which was regulated at its reference voltage level by the FC based ANPC converter absorbing the reactive power during $t=0$ to $2 \mathrm{~s}$, as shown in Fig. 14. The active power output based on wind speed profile increases that also gradually increases the reactive power absorption 


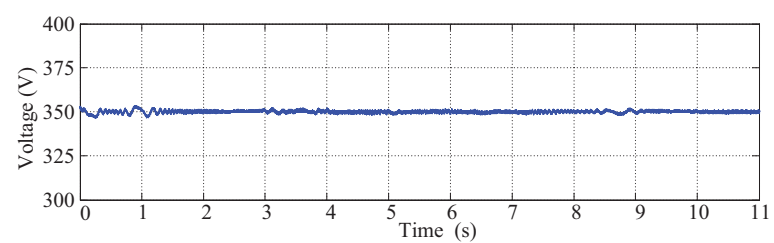

(a)

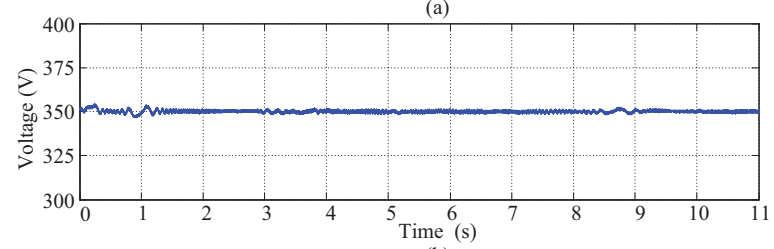

(b)

Fig. 12. PV mode, case 1: (a) voltage across $C_{1}$ (b) voltage across $C_{2}$

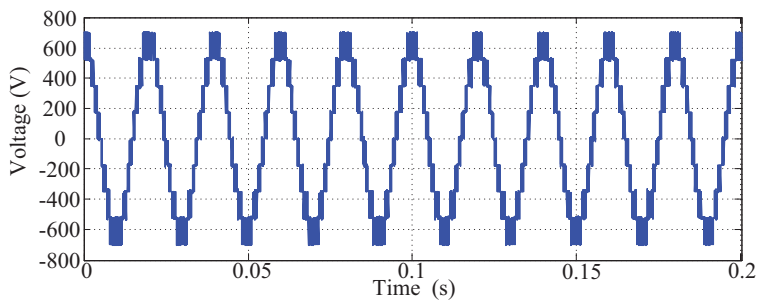

Fig. 13. PV mode, case 1: converter line-to-line voltage, $v_{\text {rab }}$ [snapshot from $t=3.5 \mathrm{~s}$ to $3.7 \mathrm{~s}$ ]

from grid. At $t=2 \mathrm{~s}$, a load $l_{1}=30 \mathrm{~kW}$ was connected to the grid through a breaker at PCC. In order to regulate the PCC voltage, reactive power injected was decreased as the amount of the active power injection increased into the grid as illustrated in Fig. 14(b). Another load $l_{2}=60 \mathrm{~kW}$ was connected to the grid at $t=4 \mathrm{~s}$, Fig. 14(a) and (b) illustrate that when active power generation decreases, the reactive power injection increases to regulate the PCC voltage. The loads $l_{1}$ and $l_{2}$ were disconnected from the grid at $t=5 \mathrm{~s}$ and $t=8 \mathrm{~s}$ respectively. The behavior of PCC voltage and the voltage across dc-link were controlled at their references levels as shown in Fig. 14(c) and (d) respectively. The voltages across the dc-link capacitors were regulated at their reference levels as shown in Fig. 15(a) and (b) for various operation modes.

In case 3 , the regulation of voltage at PCC by reactive power exchange when $P_{r}=0$ was investigated. In this case, the required load power $\left(P_{l}\right)$ was supported from the grid. The voltage at PCC was support by the reactive power injection from the FC based ANPC converter. Fig. 16(a) illustrates the behavior of active power exchange at PCC for various loads. The reactive power was injected into the grid as illustrated in Fig. 16(b) to regulate the PCC voltage. The regulation of PCC voltage was shown in Fig. 16(c). The behavior of voltages across the dc-link capacitors were regulated as shown in Fig. 17(a) and (b).

\section{B. PMSG Based Grid-Connected System as PQ Bus}

Grid-connected system operates as a PQ bus by exchanging active and reactive power to grid based on their reference values. The total active power generated from the wind energy
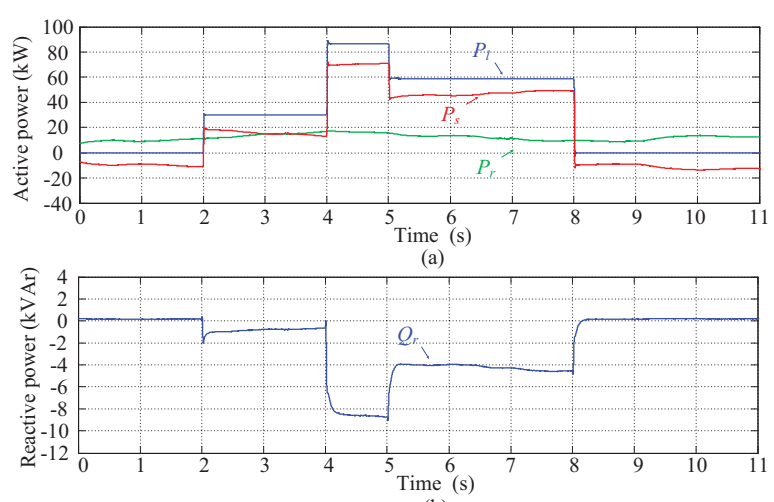

(b)
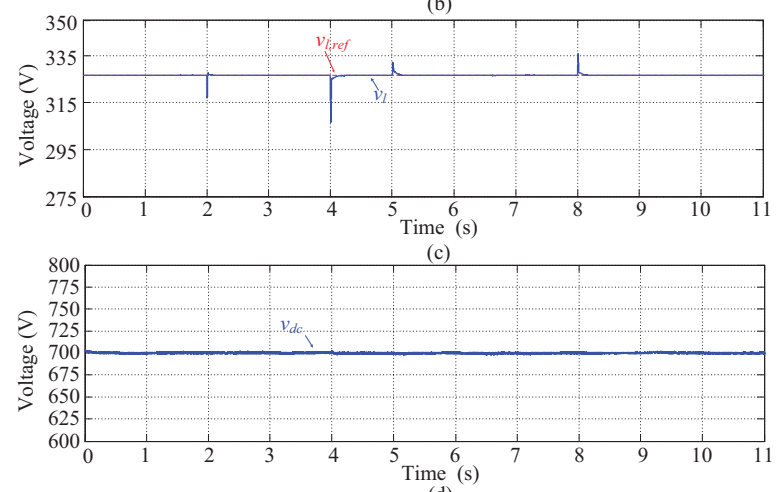

Fig. 14. PV mode, case 2: (a) active power exchange at PCC, $P_{r}, P_{s}, P_{l}$ (b) reactive power, $Q_{r}(\mathrm{c})$ PCC voltage, $v_{l}$ (d) the voltage across dc-link, $v_{d c}$
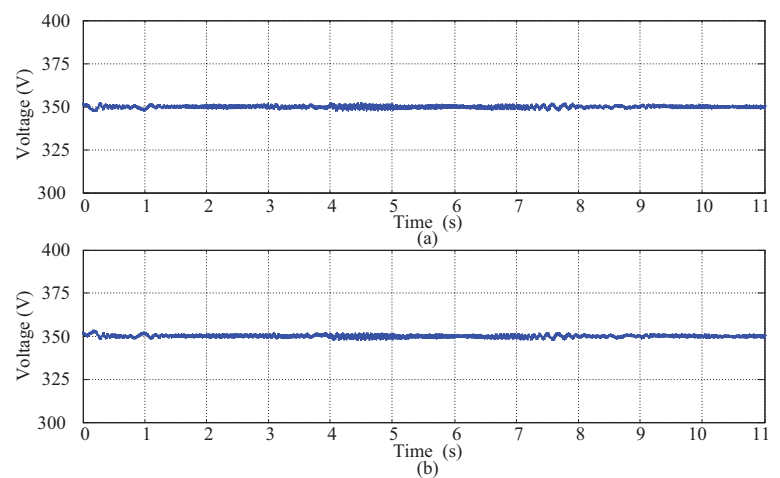

Fig. 15. PV mode, case 2: (a) voltage across $C_{1}$ (b) voltage across $C_{2}$

system was transferred to the grid using dc-link voltage controller. The reactive power reference was obtained from (18) due to which the grid-connected system operates at constant power factor based on the active wind power generation. The reactive power capability was constrained by the apparent power limitation of the FC based ANPC converter.

$$
Q_{\text {rref }}=P_{r} \tan \left(\cos ^{-1} \frac{S_{q r}^{s v}}{\sqrt{\left(S_{p r}^{s v}\right)^{2}+\left(S_{q r}^{s v}\right)^{2}}}\right)
$$

The FC based ANPC converter injects the reactive power $\left(Q_{r}\right)$ operating the converter at 0.9 power factor which varies the PCC voltage at its reference level as shown in Fig. 18. It was observed that most of the time, the PCC voltage was 

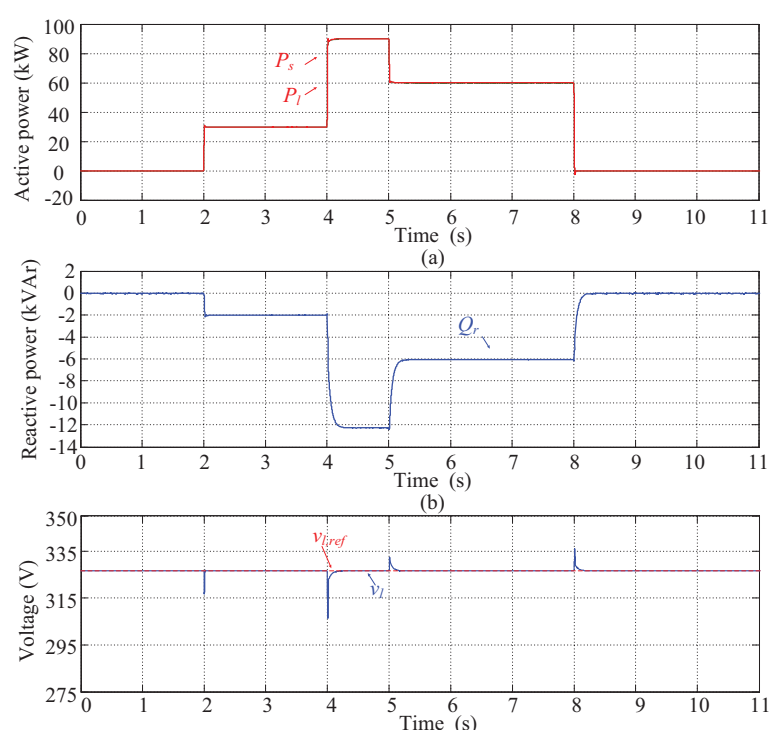

(c)

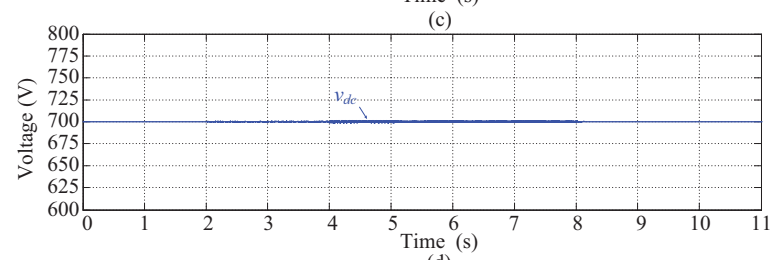

(d)

Fig. 16. PV mode, case 3: (a) active power exchange at PCC, $P_{s}, P_{l}$ (b) reactive power, $Q_{r}$ (c) PCC voltage, $v_{l}$ (d) the voltage across dc-link, $v_{d c}$

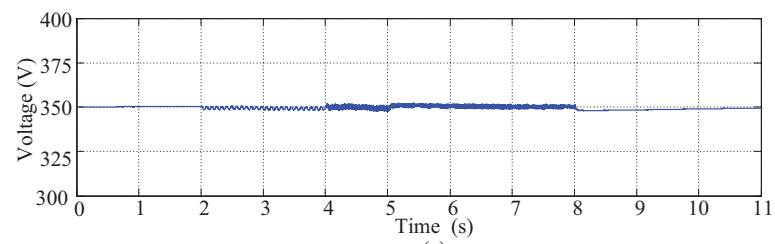

(a)

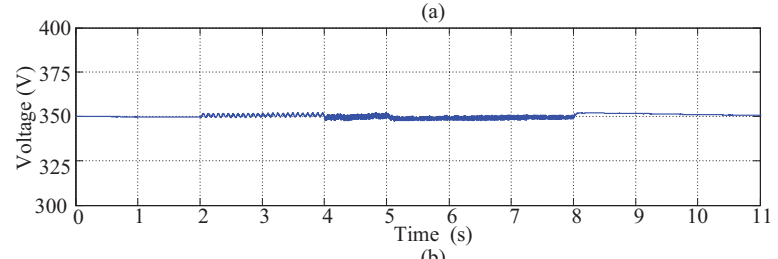

(b)

Fig. 17. PV mode, case 3: (a) voltage across $C_{1}$ (b) voltage across $C_{2}$

above its reference value depending on the load fluctuation at PCC. The variation of load at PCC was considered same as that considered in PV mode operation. Fig. 18(a) and (b) demonstrates the behavior of $P_{r}, P_{s}, P_{l}$ and $Q_{r}$ respectively. Fig. 18(d) shows the dc-link voltage to demonstrate its behavior at its reference level. Fig. 19 illustrate voltages acorss dc-link capacitors voltages for various operating modes.

\section{CONCLusions}

In this paper, the performance of the grid-connected fivelevel FC based ANPC converter wind energy system has been evaluated subject to PQ and PV bus operating modes using the proposed control strategy based on voltage sensitivity
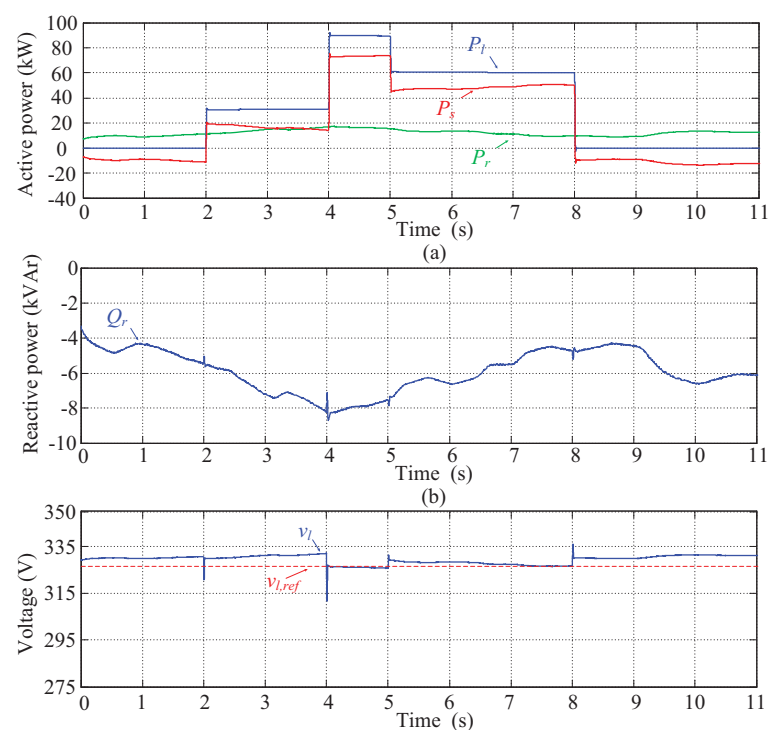

(c)

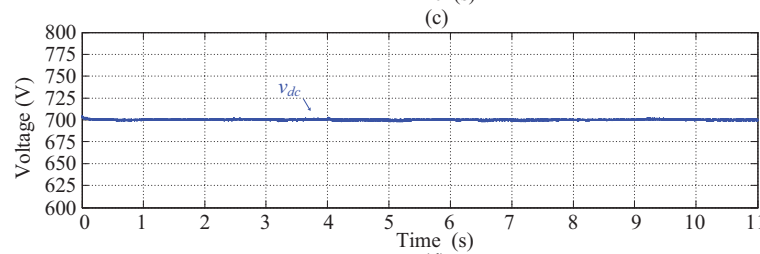

(d)

Fig. 18. PQ mode: (a) active power exchange at PCC, $P_{r}, P_{s}, P_{l}$ (b) reactive power, $Q_{r}$ (c) PCC voltage, $v_{l}(\mathrm{~d})$ the voltage across dc-link, $v_{d c}$
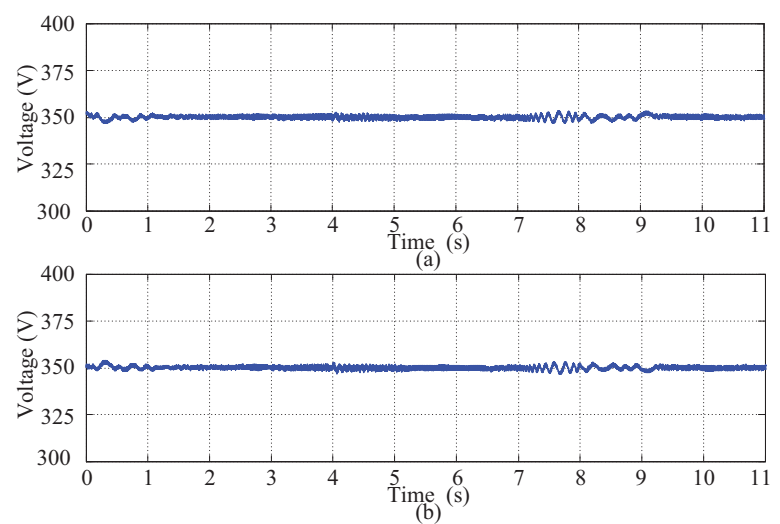

Fig. 19. PQ mode: (a) voltage across $C_{1}$ (b) voltage across $C_{2}$

parameters at point of common coupling. The grid-connected wind energy system in PQ bus mode has been operating at constant power factor varying the exchange of reactive power into the distribution network based on wind power generation. The simulation studies demonstrate that regulating the power factor based on active power generation results in adverse voltage control at PCC. In PV bus operating mode, the PCC voltage has been regulated at its reference value by exchanging reactive power into the distribution network depending on active power generation. The performance of the grid-connected system has been evaluated subject to variable reactive power control. The variable reactive power control 
regulates the voltage at the PCC depending on the amount of active power generation. The flying capacitor voltages and dclink capacitors have been stabilized under various operating conditions by implementing the proposed flying capacitor voltage control strategy together with neutral point voltage compensator.

\section{ACKNOWLEDGEMENT}

This work is supported by Essential Energy and the Australian Research Council (ARC) Linkage Grant, LP100100618.

\section{REFERENCES}

[1] F. Blaabjerg, Z.Chen, and S. B. Kjaer, "Power electronics as efficient interface in dispersed power generation systems," in IEEE Trans. on Power Electron., vol. 19, no. 5, pp. 1184-1194, Sep. 2004.

[2] J. M. Carrasco, L. G. Franquelo, J. T. Bialasiewicz, E. Galvan, R. C. Portillo Guisado, M. A. M. Prats, J. I. Leon, and N.Moreno-Alfonso,"Powerelectronic systems for the grid integration of renewable energy sources: A survey, in IEEE Trans. Ind. Electron., vol. 53, no. 4, pp. 1002-1016, Jun. 2006.

[3] A. Alessandro, B. Enrico, B. Morris, S. Giuseppe, T. Enrico, and U. Giovanni, "LV DC distribution network with distributed energy resources: Analysis of possible structures," in Proc. of CIRED, 2005, pp. 1-5.

[4] V. Musolino, L. Piegari, E. Tironi, L. Martini, A. Brambilla, and C. Tornelli, "Simulations and field test results for potential applications of LV DC distribution network to reduce flicker effect," in Proc. of ICHQP Conf., 2010, pp.1-6.

[5] J. Yang, J. E. Fletcher, and J. O' Reilly, "Multiterminal DC wind farm collection grid internal fault analysis and protection design," in IEEE Trans. on Power. Del., vol. 25, no. 4, pp. 2308-2318, Oct. 2010.

[6] E. Haque, M. Negnevitsky, and K. M. Muttaqi, "A novel control strategy for a variable-speed wind turbine with a permanent-magnet synchronous generator," in IEEE Trans. on Ind. Appl., vol. 46, no. 1, pp. 331-339, Jan. 2010.

[7] S. Song, S. kang and N. Hahm, "Implementaion and control of grid connected ac-dc-ac power converter for variable speed wind energy conversion system," in Proc. IEEE Aplplied power Electronics Conf. and Exp. (APEC), 2003, pp. 154-158.

[8] E. Twining and D. G. Holmes, "Grid current regulation of a three-phase voltage source inverter with an LCL input filter, in IEEE Trans. Power Electron., vol. 18, no. 3, pp. 888-895, May 2003.

[9] S. Kouro, M. Malinowski, K. Gopakumar, J. Pou, L. G. Franquelo, B. Wu, J. Rodriguez, M. A. Perez, and J. I. Leon, "Recent advances and industrial applications of multilevel converters," IEEE Trans. Ind. Electron., vol. 57, no. 8 , pp. 2553-2580, Aug. 2010 .

[10] J. Rodriguez, L. G. Franquelo, S. Kouro, J. I. Leon, R. Portillo, M. Prats, M. Perez, "Multilevel converters: An enabling technology for high-power applications, in Proc. of the IEEE, Vol. 97, No. 11, Nov. 2009, pp. 17861817.

[11] M. Malinowski, W. Kolomyjski, M. P. Kazmierkowski, and S. Stynski, "DSP/FPGA control for variable-speed wind turbines, in Proc. IEEE Ind. Electron. Conf., 2006 , pp. 5161-5166.

[12] V. Yaramasu and B. Wu, "Three-level boost converter based medium voltage megawatt PMSG wind energy conversion systems," in Proc. IEEE Energy Conversion Congress and Exposition, 2011, pp. 561-567.

[13] M. G. Molina and P. E. Mercado, "A new control strategy of variable speed wind turbine generator for three-phase grid-connected applications," in Proc. of IEEE/PES Conf., 2008, pp.1-8.

[14] P. Barbosa, P. K. Steimer, M. Winkelnkemper, J. Steinke, and N. Celanovic, "Active-neutral-point clamped (ANPC) multilevel converter technology," in Proc. of EPE Conf., 2005, pp.11-14.

[15] S. R. Pulikanti and V. G. Agelidis, "Hybrid flying capacitor based activeneutral-point-clamped five-level converter operated with SHE-PWM," in IEEE Trans. on Ind. electron., vol. 58, no. 10, pp. 69-77, Oct. 2011.

[16] S. Morimoto, H. Nakayama, M. Sanadai, and Y. Takeda "Sensorless output maximization control for variable-speed wind generation system using IPMSG," in IEEE Trans. on Ind. Appl., vol. 41, no. 1, pp. 60-67, Jan. 2005.

[17] L. M. Tolbert and T. G. Habetler, "Novel multilevel inverter carrierbased PWM method," in IEEE Trans. on Ind. Appl., vol. 35, no. 5, pp. 1098-1107, Sep. 1999.
[18] N. R. Ullah, K. Bhattacharya, and T. Thiringer, "Wind farms as reactive power ancillary service providers-technical and economic issues", in IEEE Trans. Energy Conversion, vol. 24, no. 3, pp. 661-672, Sep. 2009.

[19] C. Du, A. Sannino, and M. H. J. Bollen, "Analysis of the control algorithms of voltage-source converter HVDC, Proc. of IEEE Powertech Conf., 2005, pp.1-7.

[20] M. F. Mogos and X. Guillaud, "A voltage regulation system for distributed generation, Proc. of IEEE PES Conf., 2004, pp.787-794.

[21] M. A. Kashem and G. Ledwich, "Distributed generation as voltage support for single wire earth return systems, in IEEE Trans. Power Del., vol. 19, no. 3, pp. 1002-1011, Jul. 2004.

[22] L. Holdsworth, X. G. Wu, J. B. Ekanayake, and N. Jenkins, "Direct solution method for initializing doubly-fed induction wind turbines in power system dynamic models, in Proc. Inst. Elect. Eng., Gen., Transm., Distrib., vol. 150, no. 3, pp. 334342, May 2003. 